\title{
A importância da análise didática dos erros matemáticos como estratégia de revelação das dificuldades dos alunos
}

\author{
The importance of didactic analysis of mathematical errors as the developing strategy of \\ the difficulties of students
}

\author{
Maria Luisa Perdigão Diz Ramos \\ mlperdigao@yahoo.com.br
}

\begin{abstract}
Resumo
Neste trabalho são apresentadas teorias e acepções do erro, além de duas formas didáticas de analisar os erros nas produções escritas dos alunos. Essas teorias, acepções e formas didáticas de análise dos erros foram utilizadas pela autora em sua investigação de doutorado, que teve como objetivo identificar, analisar e classificar os tipos de erros matemáticos cometidos por alunos do $1^{\circ}$ ano da educação profissional tecnológica de nível médio do curso Técnico em Eletrotécnica do CEFET-MG, em conteúdos propostos na $1^{\mathrm{a}}$ avaliação institucional. Assim, a finalidade principal deste artigo é descrever a importância da análise do erro, pois nem sempre o aluno consegue identificá-lo e nem mesmo perceber que errou. Por isso, é fundamental o professor identificar, analisar e categorizar o erro do aluno, pois, somente assim, será capaz de tratar o erro de forma didática, tornando possível a reconstrução do conhecimento e a supressão da recorrência do erro.
\end{abstract}

Palavras-chave: Erro. Dificuldade. Análise didática dos erros. Nova pedagogia.

\begin{abstract}
In this work are presented theories and meanings of the error and two ways to analyze errors in students' written productions. These theories, meanings and forms of analysis of the errors were used by the author in his doctoral research, which aims to identify, analyze and classify the types of mathematical errors committed by students from the first year of professional and technological education of middle level course technician Electrotechnical from the CEFET-MG, in proposed contents in first institutional assessment. So the main purpose of this article is to describe the importance of error analysis, because not always the student can identify your mistake and not even realize that was wrong. Therefore, it is essential, the teacher identify, analyze and categorize the error of the student, because only thus will be able to handle the error in a didactic way, making possible the reconstruction of knowledge and the suppression from the error recurrence.
\end{abstract}

Keywords: Error. Difficulty. Didactic analysis of errors. New pedagogy.

\section{Introdução}

Primeiramente, é muito importante definir o significado das palavras dificuldade e erro para melhor entendimento da relação existente entre elas. As duas palavras foram pesquisadas no dicionário eletrônico Houaiss da Língua Portuguesa (2001, n.p.). A palavra “dificuldade" tem como significado: "o que impede, embaraça; estorvo, obstáculo". A palavra "erro" significa: "juízo ou julgamento em desacordo com a realidade observada; engano". 
Com os significados relatados, percebe-se que a palavra dificuldade significa barreiras encontradas na busca do conhecimento. Portanto, o erro é uma consequência disso, sendo um dos seus significados o engano. Na sequência, serão apresentados alguns conceitos sobre erro, tomando como base o ponto de vista de alguns pesquisadores.

Gamboa (1997), quando professor da Pontifícia Universidad Católica del Peru, descreveu em seu trabalho que "o estudo do conhecimento humano, da capacidade do homem para compreender, tem sido sempre uma preocupação constante da filosofia em uma vertente denominada gnosiologia ${ }^{1}$ " (p. 1, tradução da autora). Diante disso, o autor afirma que o erro é atribuído a uma disposição de considerar concepções e procedimentos que foram desenvolvidos deficientemente como verdadeiros, nos quais foram incluídas interpretações falsas ou ideias conflitantes.

Acrescentando a essa colocação, Pinto (2000), pesquisadora e doutora na área de ensino e educação matemática, afirma que o erro faz parte do ato de aprender, isto é, ele é parte integrante de um conhecimento provisório. A autora descreve ainda que, pelo fato do aprendizado ser um ato dinâmico, o erro passa por transformações, dependendo de situações conflitantes durante o desenvolvimento do indivíduo.

A origem do erro é localizada pelo filósofo Descartes em duas atitudes (o qual chamou de atitudes infantis): a prevenção e a precipitação. Chaui (2005) descreve que para Descartes a prevenção "é a facilidade com que nosso espírito se deixa levar pelas opiniões e ideias alheias, sem se preocupar em verificar se são ou não verdadeiras” (p. 127); já a precipitação "é a facilidade e a velocidade com que nossa vontade nos faz emitir juízos sobre as coisas antes de verificarmos se nossas ideias são ou não são verdadeiras” (p. 127).

No campo semântico, De La Torre (2007), doutor em Filosofia e Letras pela Universidade de Barcelona, descreve o erro usando quatro pontos cardeais: efeito destrutivo, deturpativo, construtivo e criativo. $\mathrm{O}$ erro é apontado por ele de uma forma binária: a negativa (efeito destrutivo e deturpativo) e a positiva (construtivo e criativo). Na forma negativa, o erro tem um efeito destrutivo, isto é, ele provoca falhas irreversíveis; já na forma de estímulo criativo o erro pode ser considerado como um instrumento de progresso.

\footnotetext{
${ }^{1}$ Teoria geral do conhecimento humano, voltada para uma reflexão em torno da origem, natureza e limites do ato cognitivo, freq. apontando suas distorções e condicionamentos subjetivos, em um ponto de vista tendente ao idealismo, ou sua precisão e veracidade objetivas, em uma perspectiva realista; gnoseologia, teoria do conhecimento. (HOUAISS, 2001, n.p.).
} 
Além disso, De La Torre (2007) assinala ainda que o erro pode indicar duas situações: resultado e processo. O erro visto como resultado tem um significado negativo, isto é, apresenta um efeito deturpativo ou destrutivo. Visto como processo pode levar a um procedimento construtivo, método de descoberta científica ou como uma forma de transmissão didática, sendo vista, portanto, como um estímulo criativo. Essa criatividade, conforme apontada pelo autor, "[...] não está, como é natural, no erro, mas nas pessoas que são capazes de gerar novas idéias apoiando-se nele" (p. 15).

A sinopse sobre os diversos significados do erro apresentada por De La Torre (2007) é descrita em quatro categorias: pensamento, linguagem, ação (proceder) e erro voluntário (engano). Dentro de cada categoria, o erro, como efeito deturpador, carrega de forma implícita um significado negativo. Conforme o autor, os significados para a categoria pensamento são confusão, desacerto, equívoco, falha, inadvertência, inexatidão, irracionalidade; os significados para a categoria linguagem são inconveniências, besteira, disparate, errata, mancada; já os significados para a categoria ação são desacerto, descuido, distorção, equívoco, falha; e, finalmente, os significados para a categoria erro voluntário são engano, acobertamento, fraude, hipocrisia, simulação, mentira, truque, manipulação. Logo, para o autor, "Cada categoria tem suas próprias características e seus próprios mecanismos e processos." (p. 16).

A partir do que foi exposto, é possível delinear um conceito sobre o erro numa perspectiva geral. Dessa forma, observa-se que o erro não é fruto da ignorância, pois, sendo ele cometido em função de um desconhecimento parcial, mesmo assim, ele possibilita a reconstrução de conhecimentos. Analisando o significado do erro de uma forma binária, a negativa e a positiva, o erro deve ser visto em sua forma positiva, ou seja, ele deve ser tratado a partir de uma acepção construtiva e criativa.

Durante a investigação realizada, não foram encontrados autores que apresentam um significado para a palavra dificuldade, exceto a afirmação da relação existente entre as palavras dificuldade e erro feita por Socas (apud LUPIÁÑEZ, 2013): o erro é uma manifestação visível de uma dificuldade. Portanto, será considerado aqui que, para se compreender as dificuldades, é necessário identificar os erros. 


\section{Teorias e Acepções do Erro no Processo de Aprendizagem}

Vários são os pesquisadores (RICO, 1998; PINTO, 2000; DE LA TORRE, 2007; CURY, 2008; entre outros) que vêm investigando as dificuldades e os erros cometidos por alunos. A seguir, serão abordadas as teorias e acepções do erro na aprendizagem da Matemática, sob o ponto de vista de alguns desses pesquisadores.

Thorndike (apud CURY, 2008) é um dos precursores do estudo sobre os erros, com trabalhos realizados no início do século XX. Como pai da Psicologia Educacional, Thorndike enfatizava que os interesses vitais do aluno devem ser respeitados, procurando não entediá-lo com "dificuldades inúteis". Para ele era necessário o reforço dos hábitos que permitiam ao aluno a prática dos cálculos. Devido às críticas recebidas por outros colegas, que consideravam seu método baseado em exercícios repetitivos, Thorndike passou a investigar sobre dificuldades e erros relacionados com problemas que ocorrem nas operações aritméticas fundamentais, tornando-se um dos pioneiros sobre os estudos relacionados aos erros.

O psicólogo russo Krutetskii (apud CURY, 2008) mostra em seu trabalho a importância de se analisar o processo e não apenas o produto. Como exemplificado pelo autor, não se deve avaliar somente a alternativa assinalada em uma questão de múltipla escolha ou o resultado apresentado em uma questão aberta; é necessário também analisar o raciocínio apresentado durante o processo de resolução da questão. Analisando o processo dessa maneira, é possível perceber as habilidades matemáticas dos estudantes, além das dificuldades por eles apresentadas. O pesquisador afirma também que, nessa forma de análise, podem-se questionar os estudantes sobre os erros cometidos e ajudá-los na reconstrução do conhecimento.

Os pesquisadores mencionados, precursores nos estudos sobre erros, são referenciados em vários trabalhos, entre eles, o de CURY (2008) e o de BASTOS (2013). Ponderando sobre suas afirmações, constata-se que é de suma importância o professor analisar todo o procedimento utilizado pelo aluno na resolução de uma questão e que o erro deve ser visto como manifestação de um conhecimento que o aluno construiu, portanto, não pode ser simplesmente desprezado. Ao desprezá-lo, o professor parte do pressuposto de que o aluno não possui nenhum conhecimento prévio, o que não é verdade, na maioria das vezes.

O espanhol e educador matemático Rico (1998) aponta em seu trabalho várias pesquisas (RADATZ，1979; MOVSHOVITZ-HADAR，ZAVSLASKI，INBAR，1987; entre outras) 
realizadas na Educação Matemática que destacam o erro como principal fonte de estudo. Menciona ainda que

o estudo dos erros, na aprendizagem de matemática, tem sido uma questão de permanente interesse na educação matemática, que tem uma longa história e que se caracteriza por aproximações e interesses muito diferentes. Em cada época a análise de erros em educação matemática tem-se orientado pelas correntes predominantes em pedagogia e psicologia; também tem estado condicionada pelos objetivos e formas de organização do currículo de matemática nos correspondentes sistemas educativos. (RICO, 1998, p. 77, tradução da autora).

Analisando o que foi apresentado até o momento, é possível verificar que, em determinado período, os pesquisadores (por exemplo, Thorndike) acreditavam que a repetição de tarefas era uma das formas que os alunos tinham para praticar o que foi ensinado, além de considerarem que, com o uso dessa prática, era possível eliminar o erro. Com a evolução dos estudos na área, a linha de pensamento dos pesquisadores sofreu modificações. Além de provocar mudanças individuais, os resultados das pesquisas vêm influenciando nas formas de organização do currículo de Matemática.

Rico (1998) afirma que o professor não pode ignorar a capacidade do aluno nem tão pouco desprezar os erros que ele comete. Corroborando com a afirmativa do autor e, analisando o erro dentro de um contexto escolar, o simples fato de o aluno cometer um equívoco, ou uma falha, ou um descuido provenientes de seu pensamento ou ação, já é o suficiente para alertar o professor de que alguma coisa está errada e que alguma atitude deve ser tomada. Usando da criatividade, o professor pode dar um enfoque didático aos erros, da mesma forma em situações problemáticas, quando as pessoas conseguem, a partir deles, realizar novas descobertas científicas.

Considerando, também, que o erro não pode ser desprezado, De La Torre (2007) propõe que

[...] o professor pode-se valer do erro em outros sentidos, como: analisando as causas do erro, adotando uma atitude compreensiva, propondo situações ou processos para que o aluno descubra as suas falhas, utilizando-o como critério de diferenciação de processos de aprendizagem, etc (DE LA TORRE, 2007, p. 15-16).

Se a partir do erro o professor é capaz de visualizar as dificuldades do aluno, então é de fundamental importância que o professor analise o erro cometido, pois, dessa maneira, poderá ajudar na superação dessas dificuldades.

Deve-se compreender que o erro não é uma meta a ser perseguida, mas também não é um resultado que deve ser ignorado, sem antes analisar o processo utilizado na resolução da 
questão, pois após a constatação do erro, devemos buscar a eliminação de sua reincidência. Segundo De La Torre (2007) "O erro é filho da mudança” (p. 49).

Conforme descrito, o erro pode ser visto de duas formas: positiva e negativa. Para ambas, o erro não apresenta conceito unívoco. Diante disso, diversos enfoques sobre o erro podem ser adotados, em especial na aprendizagem escolar. De La Torre (2007) apresenta três enfoques que proporcionam um referencial epistemológico do erro: o erro como falha punível e como efeito a ser evitado, o erro como sinal de progresso, e, finalmente, o erro como processo interativo.

No primeiro caso, o erro é visto como um resultado negativo, gerando inclusive punição caso seja cometido. Essa consequência negativa não é vista somente nos tempos atuais, pois há algum tempo as pessoas eram punidas com o uso de palmatória e por meio de outros tipos de repreensão. Hoje, uma das punições mais comuns é a exercitação, isto é, acredita-se que se o aluno realizar uma enorme lista de exercícios, sobre um determinado assunto de qualquer disciplina, conseguirá aprender o conteúdo desejado e não correrá o risco de cometer novos erros. Dessa forma, valoriza-se mais a quantidade do que a qualidade das tarefas realizadas.

O erro caracterizado pelo segundo enfoque - como sinal de progresso - apresenta uma conotação positiva. Por meio dele pode-se verificar que os resultados apresentados sobre conjecturas ou suposições levantadas sobre um determinado conteúdo não são os esperados. Então, a partir disso, novas hipóteses e investigações deverão ser formuladas. Pode-se afirmar que, nessa situação, o erro estaria funcionando como um termômetro, ou seja, um instrumento que apresenta um sinal de alerta.

No terceiro enfoque o erro é tratado como processo interativo, isto é, como resposta da interação sociocognitiva. O erro não está somente vinculado ao desenvolvimento mental do aluno, mas também faz parte das normas culturais definidas em cada sociedade. Assim, enquanto em algumas escolas os professores se preocupam com o resultado, em outras eles enfatizam mais o processo, dando ao resultado uma importância relativa.

Entende-se, então, que o erro pode indicar tanto para o aluno quanto para o professor que existem falhas em algo que foi ensinado. Se o erro for visto por ambos de forma positiva, o relacionamento entre eles proporcionará diálogo e interação, sendo possível estabelecer uma comunicação por meio da qual o professor orientará e guiará a aprendizagem do aluno de acordo com o desejado. 
Partindo das teorias e acepções do erro no processo de aprendizagem, ao se atribuir um papel positivo ao erro, pode-se reafirmar o que é dito pelos pesquisadores quando descrevem que o erro não deve ser desprezado, pois ele pode estimular o pensamento e produzir uma compreensão mais profunda de conteúdos em Matemática. Assim, é importante o professor saber o que o aluno exterioriza, em vez de apenas imaginar seus pensamentos.

Desse modo, a partir de análise realizada nas resoluções dadas pelos alunos, o professor poderá identificar não somente os erros cometidos por eles, mas, também, se as resoluções consideradas corretas não apresentam conceitos incorretos.

Assim, os erros não devem ser ignorados e muito menos usados como armadilhas em avaliações elaboradas por professores, mas devem, sim, ser classificados e analisados para que possam ser identificadas as causas e as dificuldades encontradas pelos alunos ao descreverem seu raciocínio nas respostas dadas.

Portanto, é importante que o professor veja o erro como uma fonte de informação. Desse modo, compreende-se que o erro deve ser visto com muita atenção, pois ele indica a existência de problemas que devem ser tratados. Esses problemas, muitas vezes persistentes, vão gerando novos problemas se não forem avaliados rapidamente e da melhor forma possível.

Assim sendo, por meio do erro pode-se conhecer a concepção que determinadas pessoas têm sobre alguns assuntos em Matemática e verificar se são válidas ou não. Partindo de concepções incorretas, é possível obter novos conhecimentos. A busca do conhecimento depende muito da interpretação daquilo que está sendo analisado. Portanto, na maioria das vezes, essa busca não acontece sem que o aluno demonstre incertezas.

Considera-se, então, que o erro deve ser visto pelo professor como um elemento didático e não como algo que deve ser ignorado. Tratado dessa maneira, o erro se transforma em estratégia de uma pedagogia que tem como objetivo a superação das dificuldades.

\section{O Erro sob Olhares Opostos}

Ao se considerar o erro com significados contrários, ou seja, conotação negativa ou positiva têm-se formas pedagógicas opostas para o seu tratamento: a negativa por meio da "pedagogia tradicional" e a positiva por meio da "nova pedagogia". Essas nomenclaturas são adotadas por 
Pinto (2000) e serão empregadas, dessa forma, neste artigo. A seguir, será mostrado como cada uma delas trata o erro.

Muitas vezes o erro é visto como sinônimo de fracasso, provocando no aluno um sentimento de frustração e o impedindo de buscar alternativas que possam superar sua recorrência. Confirmando isso, Pinto (2000) afirma que na "pedagogia tradicional" o erro serve como um indicador de fracasso do aluno, ou seja, no momento em que o aluno não tem espaço para cometer erros, o seu desenvolvimento fica limitado. Nesse cenário, o aluno não tem espaço para refletir sobre o erro sem que sinta medo.

Partindo do pressuposto de que o fracasso provoca o desânimo e, consequentemente, prejudica a aprendizagem, os professores passaram então a favorecer o êxito, provocando, assim, o acerto na maioria das vezes em avaliações realizadas pelos alunos. Esse tipo de procedimento é adotado pela "pedagogia tradicional”, aquela que procura evitar o erro.

Para que o erro não ocorra, esse tipo de "pedagogia" baseia-se no princípio de evitamento e no princípio de progressão graduada. Compartilhando das ideias de Pinto (2000), Starepravo (2010), aponta que

O erro é frequentemente tratado, nas escolas, como algo a ser evitado ou até mesmo eliminado. Esse tipo de tratamento advém de uma visão imediatista de aprendizagem: acredita-se que uma boa explicação por parte do professor, seguida da aplicação nos exercícios pode garantir a aprendizagem, sem levar em conta que esta trata-se, na realidade, de um processo de construção complexo que está sujeito a rupturas e reestruturações. (STAREPRAVO, 2010, 228).

Como já mencionado, infere-se que, com o propósito de se evitar o erro, criam-se tarefas programadas a fim de garantir o mecanismo didático de exercitar. Assim, o aluno se sente mais seguro e certo do êxito nas atividades desenvolvidas. É dessa forma que a "pedagogia tradicional" trata o erro, e nela o conhecimento é visto como algo já construído; o aluno tem a função de adquirir o conhecimento sem atrapalhar o andamento das atividades didáticas, ou seja, sem errar.

Acredita-se que a adoção da "pedagogia tradicional" não significa a resolução do problema do fracasso, pois o uso de tarefas programadas não garante a aprendizagem do aluno. Assim, a "pedagogia tradicional", além de estimular a reprodução e a falta de criatividade (provocada pelo imobilismo), acaba proporcionando o fracasso. Portanto, nessa "pedagogia" as pessoas (professores, alunos, pais, sociedade, entre outros) valorizam o resultado final sem se preocupar com o que deixou de ser aprendido. 
O erro na "pedagogia tradicional" é visto como um fracasso do aluno. Em uma nova visão (PINTO, 2000), o erro se torna uma conjectura integrante da construção do conhecimento. Completando o que foi dito, a autora declara que:

Diferentemente das didáticas tradicionais, em que o erro servia, geralmente, como indicador do fracasso do aluno, nas novas teorias ele se apresenta como um reflexo do pensamento da criança, sendo percebido como manifestação positiva de grande valor pedagógico (PINTO, 2000, p. 10).

Continuando, a autora descreve que o mito do erro enquanto fracasso tem, aos poucos, cedido lugar para uma "pedagogia" que o admite como elemento que, ao contrário do que se imaginava, auxilia na reconstrução do conhecimento. Estaremos nos enganando ao acharmos que não somos capazes de errar; assim, em contrapartida à "pedagogia tradicional", existe a "nova pedagogia".

$\mathrm{Na}$ "nova pedagogia", a aprendizagem é um processo dinâmico, flui nos dois sentidos: professor-aluno e aluno-professor. Nesse tipo de aprendizagem é importante o professor saber o que e como os alunos pensam no momento em que estão aprendendo (RICO, 1998; PINTO, 2000). Portanto, é importante o professor tratar o erro de uma forma mais intensa, pois, muitas vezes o erro não é simplesmente uma manifestação de falha de memória, podendo ter raízes mais profundas. Esse tratamento não deve ser feito somente pelo professor, mas também pelos próprios alunos, sob orientação daquele.

Corroborando com as ideias de Pinto (2000), acredita-se que a "nova pedagogia" não busca propriamente o erro; ele é aceito por ela como um fato que faz parte da aprendizagem, exatamente pelo motivo de que toda procura pelo conhecimento está sujeita a falhas e equívocos. Dessa forma, o erro não deve ser suprimido. O professor deve assumi-lo como uma tentativa, na qual o aluno planeja uma estratégia de ação e a coloca em prática.

Acredita-se, ainda, que esse tipo de proposta de trabalho proporciona ao aluno um ambiente escolar mais descontraído, pois, nesse ambiente, não estão incluídos atos punitivos, e sim o favorecimento do diálogo que ajuda o aluno a expor seus pensamentos sem medo de cometer erros. Assim, o trabalho em grupo, a colaboração entre colegas, o diálogo entre alunos e professores, tudo isso é permitido e faz parte do conjunto de recursos didáticos, além de ser utilizado também como objeto de avaliação.

Enfatizando o que foi descrito, De La Torre (2007) afirma que, pelo fato de a "nova pedagogia" (denominada por ele como "pedagogia do erro") se ater à análise de erros e à intervenção no processo de aprendizagem, ela se torna eficiente e não somente eficaz como a "pedagogia tradicional" (denominada por ele como "pedagogia do êxito"). Segundo o autor, 
isso se deve pelo fato de a eficácia ser definida em termos da relação objetivos-resultados, ao passo que "A eficiência é definida em termos de rentabilização de recursos, isto é, de relação entre objetivos, meios e resultados. Entre os momentos inicial (objetivos) e final (resultados), introduz a utilização de meios e recursos" (p. 79). Considera-se, assim, que a "nova pedagogia" se preocupa em avaliar as estruturas do processo ensino-aprendizagem.

Nesse sentido, De La Torre (2007) completa o que foi dito quando descreve que o erro "Utilizado como estratégia, no entanto, é positivo, desde que não se cometam excessos" (p. 77). Ele ainda usa de uma comparação para justificar o que foi descrito: "Os medicamentos curam se tomados em doses adequadas, mas são prejudiciais se abusarmos deles" (p. 77). O erro utilizado como estratégia tem um valor positivo; isso não significa que ele deva ser estimulado, muito menos provocado.

Ao fazer uma análise das duas propostas, percebe-se que o erro está sendo tratado por visões diferentes. A primeira visão refere-se à "pedagogia tradicional”, cuja crença é: aquilo que está faltando ou aquilo que está inadequado deve ser evitado. A segunda refere-se a "nova pedagogia”, aquela que valoriza o que o aluno já conhece, procurando então complementar aquilo que está faltando. A ideia de valorizar aquilo que o aluno já conhece é compartilhada por Santos e Buriasco (2008) quando afirmam que não querem saber o que apenas falta aos alunos, mas, sim, o que eles conhecem, para buscar com eles, a construção daquilo que falta.

Conforme exposto, é imprescindível concordar com os enfoques apresentados pela "nova pedagogia", pois, acredita-se que o professor deve se preocupar em analisar e identificar as causas do erro. Por isso, o professor não terá somente como atividades em sala de aula a explicação do conteúdo, o auxílio ao aluno, a correção de atividades e a avaliação do conhecimento, mas também deverá se dedicar ao diagnóstico dos motivos que levaram o aluno a cometer o erro.

De acordo com a explanação feita, considera-se que o erro é uma pista que conduz o professor na organização da aprendizagem do aluno. Nessas condições, sua maior preocupação é compreender como o aluno aprende, ao passo que na "pedagogia tradicional", centrada no professor, o importante é saber o que se ensina.

Por isso, é necessário analisar o erro nas produções escritas dos alunos, pois, assim, o professor será capaz de reavaliar o processo, propor novas estratégias didáticas e tomar atitudes que possam retificar os enganos. Assim, serão explanadas na próxima seção duas formas de analisar os erros. 


\section{Formas de Analisar os Erros}

Apesar de os erros variarem de acordo com cada disciplina e conteúdo, o professor pode se utilizar da análise de erros em diferentes disciplinas e em vários níveis de ensino. Exemplos disso são descritos em Ramos (2013) e em Ramos e Curi (2013) quando as autoras apresentam a análise de erros realizada em produções escritas de alunos na disciplina de Sistemas Digitais envolvendo circuitos lógicos, e em Ramos e Curi (2014) ao analisarem erros de Matemática em questões envolvendo função polinomial do $2^{\circ}$ grau.

Confirmando a utilização da análise de erros em diferentes disciplinas, De La Torre (2007) aponta que,

Entre as didáticas especiais que mais atenção prestaram à análise dos erros estão o estudo das línguas (em particular a segunda língua) e a matemática. Enquanto as primeiras focalizam sua atenção nos erros de execução, a matemática atende aos erros de raciocínio, de compreensão e de organização biológica da informação (DE LA TORRE, 2007, p. 128).

Assim, o autor propõe um Modelo de Análise Didática dos Erros (MADE - FIGURA 1), composto de três momentos, como qualquer procedimento sistêmico: entrada, organização (processamento) e execução (saída).

Figura 1: Modelo de Análise Didática dos Erros - MADE

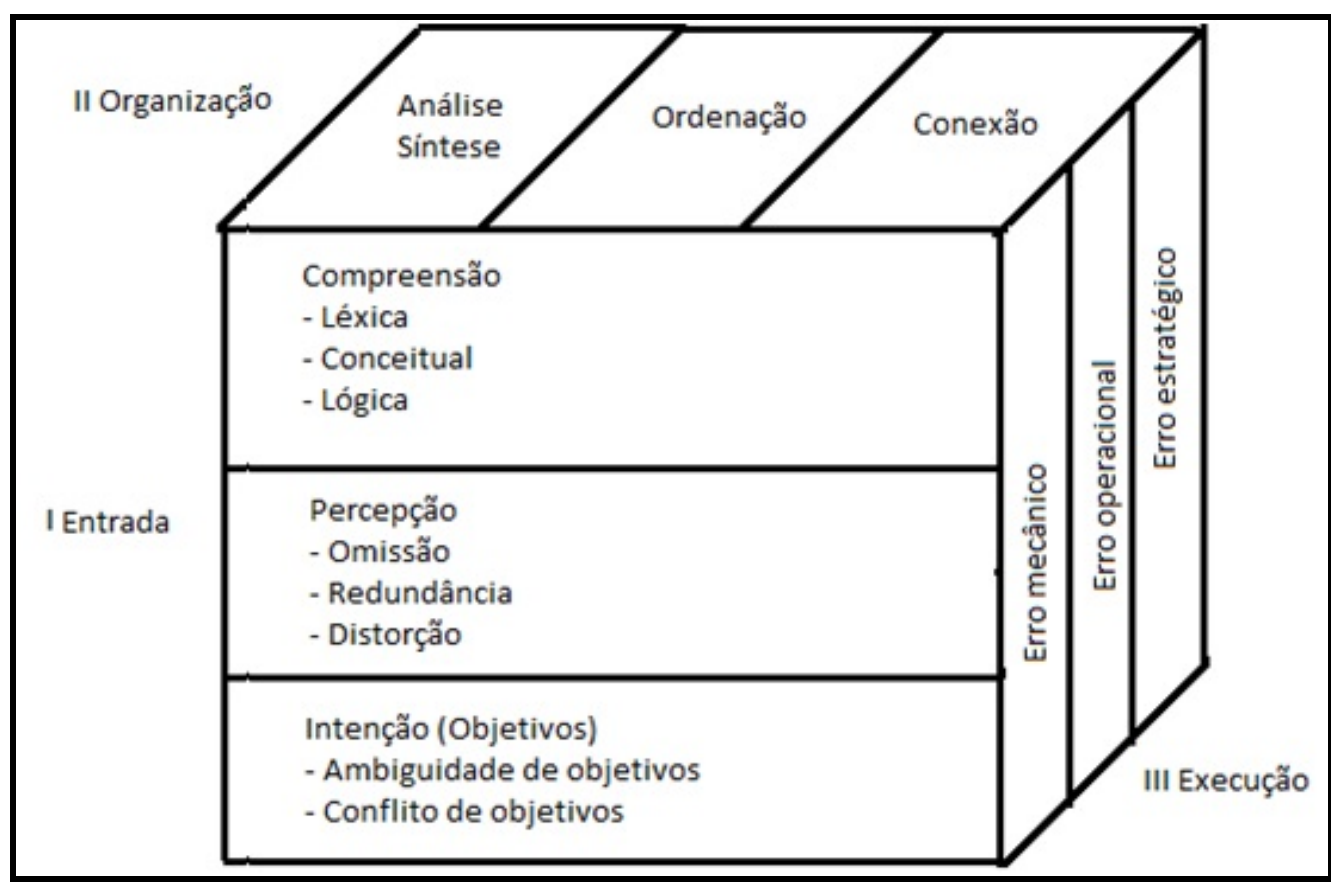

Fonte: DE LA TORRE, 2007, p. 108. 
Descreveremos na sequência, de forma detalhada, como o erro pode ser utilizado e analisado no sistema educacional por meio dos três momentos do processo apresentado no MADE.

A - Momento de Entrada é, provavelmente, o instante que pode apresentar o maior número de erros, pois ocorrem problemas de interpretação entre os dados de entrada (informações inadequadas ou insuficientes) em algum desses três planos - intenção, percepção e compreensão - e o que precisa ser exibido na saída após o processamento.

No plano das intenções, o autor abrange três situações do erro (mas representa somente duas delas no modelo apresentado - FIGURA 1), sendo a primeira caracterizada pela indefinição de metas ou falta de clareza, ou seja, o aluno, por um lado, não compreende o que está sendo solicitado pelo professor. Por outro lado, o professor não deixa claro o que ele quer que seja realizado e nem para que serve a atividade, gerando ambiguidade de metas. Como exemplo do que foi dito, o autor descreve que basta entregarmos uma folha com a seguinte instrução: “escrevam”. Logo, surgirão várias perguntas tentando esclarecer as intenções. Percebe-se então que a clareza de objetivo é importante, pois é a forma de se ajustar as atividades propostas pelo professor aos alunos.

Ainda no plano das intenções, o autor descreve que a segunda situação é quando ocorre confusão do objetivo ou da intenção. Os erros cometidos nessa fase acontecem pela falta de maturidade do aluno em relação ao tipo de objetivo apresentado em uma atividade. Para que não ocorram erros desse tipo, os objetivos de uma atividade devem ser traçados pelos professores de acordo com o nível de conhecimento do aluno. Um exemplo dado pelo autor é quando um professor apresenta um problema de Matemática para alunos de seis anos, sendo que é adequado para alunos de nove anos.

Os erros cometidos na terceira situação, segundo o autor, são provenientes do conflito de objetivos ou do desvio da meta fixada. Esse tipo de erro ocorre quando o aluno vai além daquilo que foi solicitado, mas desviando do caminho correto a ser seguido, como por exemplo, quando se interessa por uma parte do assunto e se esquece de desenvolver o restante da questão.

De La Torre (2007) menciona que os erros correspondentes à categoria das intenções podem ser facilmente evitados, pois, na maioria das vezes, o próprio professor é o principal responsável pela indução do aluno ao erro. 
No segundo plano, plano das percepções, ainda no momento de entrada, o autor afirma que os erros cometidos pela inadequada percepção da informação são em sua maioria de responsabilidade da metodologia docente ou da capacidade discente. Três são as modalidades da categoria de percepção: erros de omissão, de redundância e de distorção.

Os primeiros, erros de omissão, são devido à ausência de informação suficiente. Muitas vezes o professor acha que os alunos possuem o conhecimento de um conteúdo e dá isso por sabido. De La Torre (2007) menciona uma frase que muitas vezes é utilizada por professores em sala de aula: "Isto vocês já sabem de anos anteriores." (p. 112). Assim, o professor deixa claro que não é preciso explicar aquele conteúdo.

$\mathrm{O}$ autor revela ainda que alguns alunos cometem erros devido à redundância de informação (segundo tipo de erro descrito pelo autor nesse plano). A repetição costuma ajudar alguns, mas atrapalha outros. Dessa forma, muita informação nova dificulta a assimilação, ou seja, excessiva redundância leva à ineficácia.

O último tipo de erro no plano das percepções são os erros de distorção. Eles, normalmente, acontecem quando a informação é pouco clara, confusa, ambígua e, algumas vezes, estranha aos interesses cognitivos. Às vezes, o aluno sente que sabe, mas distorce, pelo fato de simplificar tanto os dados que acaba alterando o significado deles. Muitas vezes os alunos não conseguem distinguir entre a própria interpretação subjetiva dos fatos e os fatos mesmos, supondo, assim, que sua interpretação é correta.

O último plano do momento de entrada, de acordo com De La Torre (2007), é o plano da compreensão, no qual estão os erros de compreensão léxica, conceitual ou lógica. São erros que acontecem geralmente pela falta de compreensão da tarefa. Ao compreender um conteúdo o aluno deve ser capaz de expressá-lo com sua própria linguagem; quando isso não é possível, o aluno acaba cometendo erros dessa natureza. Erros de compreensão léxica ocorrem, por exemplo, no uso de palavras novas ou difíceis em atividades. Para o autor, quando o aluno sai de uma sala de aula sem compreender a matéria, ele terá grandes chances de cometer erros conceituais, caso isso não seja compensado com muitas horas de estudo em casa. Os erros de compreensão lógica são descritos pelo autor como fruto do funcionamento mental. Ele cita que não é fácil distinguir um erro de compreensão conceitual de um erro de compreensão lógica. 
B - Momento de Organização dos Dados é o próximo passo a ser realizado, após a obtenção das informações de entrada. É nesse momento que os processos cognitivos do aluno são colocados em prática. Esses tipos de erros estão associados à análise e síntese da informação obtida, à ordenação dessa informação e à sua conexão com o conhecimento. Segundo De La Torre (2007), "Os erros de organização ocorrem quando o sujeito trata de mudar a informação de que dispõe para dar com a resposta que lhe é pedida" (p. 118). O aluno pode cometer erros nas diversas etapas descritas anteriormente ao organizar incorretamente as informações. Esses erros ocorrem ao analisar e sintetizar as informações de entrada ao ordená-las em sequência ou ao fazer conexões dessas informações com o conhecimento que possui.

Um exemplo de análise e síntese descrito em De La Torre (2007) é o seguinte

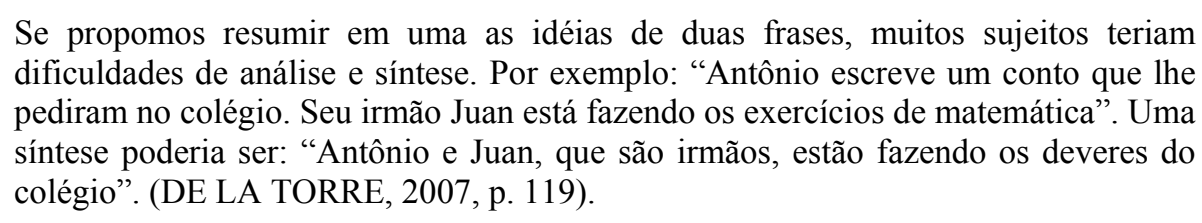

Assim, vê-se que a síntese está associada à capacidade de análise do que está sendo lido.

A ordenação é fundamental não só para tomar decisões, mas para resolver problemas. Sequenciamos as ideias tanto na fala, quanto na escrita. Um exemplo de ordenação e sequenciação da informação dado pelo autor é o aluno ordenar frações da maior para a menor levando em consideração somente o numerador.

Os erros de conexão acontecem quando os alunos não conseguem transferir conhecimentos que já possuem para novas situações. Um exemplo descrito por De La Torre (2007) é que alguns alunos do $6^{\circ}$ ou $7^{\circ}$ ano do Ensino Fundamental não conseguem identificar um triângulo retângulo quando o ângulo reto não está na base.

C - No Momento de Execução, os erros são cometidos com mais frequência por alunos que gostam de arriscar novos caminhos na resolução de um problema, sendo muito comum a ocorrência com alunos hiperativos. Esses erros são identificados por De La Torre (2007) como erros mecânicos - acontecem quando há uma troca de sinal, de letras ou até mesmo de palavras; erros operacionais - os quais têm o nervosismo como uma das causas frequentes, ocorrendo ao se operar ou executar um procedimento; e, finalmente, erros estratégicos - são erros de procedimento, ou seja, acontecem quando o aluno comete um equívoco na utilização de uma estratégia adequada ao resolver um problema. 
A partir da análise de erros, é possível perceber os erros cometidos em qualquer um dos três momentos (entrada, organização e execução da informação), trazendo, assim, contribuições para o professor e para o aluno, pois, como aponta De La Torre (2007), “[...] os erros de execução e de organização têm a ver principalmente com as aptidões pessoais, e os erros de entrada estão muito condicionados pela atuação do professor e pelo método empregado" (p. 130).

O MADE é um modelo proposto em De La Torre (2007), mas existem outras formas de se analisar os erros; uma delas será mostrada a seguir.

Conforme Pinto (2000), na "nova pedagogia" não é só o professor que exerce o papel de analisar os erros, compete também ao aluno esse papel. Para que o aprendizado tenha um caráter construtivista é necessária a participação do aluno de forma ativa nessa construção do conhecimento. Quando o aluno consegue identificar o erro, ele se torna capaz de corrigi-lo. Nessa situação, a autora descreve que o erro passa a ser “observável” para o aluno.

Para isso, a autora descreve uma forma de classificar e ordenar as respostas dadas pelos alunos, segundo seu nível de desenvolvimento, por meio da teoria psicogenética. Essa teoria, apresentada por Pinto (2000), é agrupada em três diferentes níveis:

Nível A: O aluno é indiferente ao erro, pois não compreende e nem resolve o problema proposto. Ele não consegue identificar as relações entre a forma correta e a forma errada, não reconhece o erro. Nessa situação não adianta o professor intervir de forma rotineira, como, por exemplo, sugerindo repetição de tarefas, pois nesse caso os erros são, na maioria das vezes, de ordem conceitual. A repetição nessas situações faz com que o erro se torne sistemático. Assim, cabe ao professor uma intervenção com o aluno para ajudá-lo a compreender aquilo que não consegue perceber.

Nível B: $O$ aluno consegue perceber o erro como algo que precisa ser retificado, mas não consegue superá-lo sozinho. Esses erros são gerados, por exemplo, a partir da incompreensão ou distração do que foi pedido. Eles podem ser superados com a ajuda do professor, dos pares ou dos livros.

Nível C: O aluno tem consciência do seu erro, ele sabe que errou e porque errou. Por isso, nessa situação, o erro é considerado “observável”. Na maioria das vezes, o próprio aluno 
consegue corrigir o seu erro e também se encontra em condições de ajudar os seus pares. Esses erros ocorrem por "distração" e, às vezes, nem são considerados erros.

Ao se analisar os níveis descritos anteriormente, percebe-se que é fundamental que o erro seja “observável” pelo aluno, pois, somente assim, ele poderá corrigi-lo, superá-lo e ainda ajudar seus colegas a fazerem o mesmo. Dessa forma, o aluno torna-se capaz de aprender com os próprios erros. Há de se considerar essa possibilidade desde que haja um rompimento por parte do professor com a "pedagogia tradicional", ou seja, analisar o erro a partir de uma perspectiva construtivista, pois, nessa perspectiva, tanto o erro quanto o acerto fazem parte do processo de descoberta.

Utilizando-se dessas ou outras formas de analisar o erro, o professor pode criar situações nas quais os alunos sejam encorajados a analisar e retificar seus próprios erros. Além disso, o professor pode transformar os erros que são constituídos de conhecimento em questões que podem ser trabalhadas por ele e pelos alunos, promovendo com isso o aprendizado.

\section{Considerações Finais}

A partir das exposições feitas, é fundamental destacar as questões que devem ser consideradas pelo professor na análise dos erros cometidos por alunos em suas produções escritas.

A análise da produção escrita acompanhada da análise do erro, quando realizada de forma detalhada, pode contribuir para uma melhor compreensão e aprendizagem da Matemática.

É importante a criação ou a utilização de categorias já existentes que facilitem a identificação das dificuldades que levam o aluno a cometer determinado erro. Uma das formas de se analisar o erro é a utilização do Modelo de Análise Didática dos Erros (MADE) como guia, tanto na investigação quanto na análise e tratamento didático do erro (DE LA TORRE, 2007). Outra forma é a utilização da teoria psicogenética (PINTO, 2000) como alternativa de classificar e ordenar as respostas dadas pelos alunos, segundo seu nível de desenvolvimento.

O erro deve ser visto de forma positiva e criativa, além disso, a pedagogia adotada pelo professor deve basear-se na "didática do erro", a qual está centrada nos processos, nas estratégias e nos procedimentos e não baseada somente no domínio do conteúdo.

O erro não pode ser desprezado, pois revela um conhecimento que o aluno já possui. Por meio do erro é possível estimular o pensamento e proporcionar uma compreensão mais profunda de conteúdos em Matemática. 
Os erros devem ser discutidos e usados como um método de aprendizagem, por esse motivo, os professores devem se preocupar muito mais com o processo do que com o produto das produções escritas. Dessa maneira, o erro será visto de forma construtivista.

$\mathrm{Na}$ "nova pedagogia", a aprendizagem é um processo dinâmico, flui nos dois sentidos: professor-aluno e aluno-professor. Nesse tipo de aprendizagem, é importante o professor saber o que e como os alunos pensam no momento em que estão aprendendo. Ela não busca propriamente o erro; ele é aceito por ela como um fato que faz parte da aprendizagem, exatamente pelo motivo de que toda procura pelo conhecimento está sujeita a falhas e equívocos. Nessa "pedagogia" não é só o professor que analisa os erros; compete também ao aluno essa tarefa. Para que o aprendizado tenha um caráter construtivista é necessária a participação do aluno de forma ativa nessa construção do conhecimento. Quando o aluno consegue identificar o erro, ele então se torna capaz de corrigi-lo.

O erro pode ser considerado uma pista para conduzir o professor na organização da aprendizagem do aluno, pois, nessas condições, a maior preocupação do professor é compreender como o aluno aprende. Partindo dos indicativos do erro, o professor será capaz de reavaliar o processo, propor novas estratégias didáticas e tomar atitudes que possam retificar os enganos.

\section{Referências}

BASTOS, A. S. A. M. Análise de erros matemáticos na resolução de problemas aplicados à física elétrica. 2013. 199 f. Tese (Doutorado em Ensino de Ciências e Matemática)Universidade Cruzeiro do Sul, São Paulo, 2013.

CHAUI, M. Convite à filosofia. 13. ed. São Paulo: Ática, 2005.

CURY, H. N. Análise de erros: o que podemos aprender com as respostas dos alunos. 1. ed. Belo Horizonte: Autêntica, 2008. Coleção Tendências em Educação Matemática, p. 112.

DE LA TORRE, S. Aprender com os erros: o erro como estratégia de mudança. Porto Alegre: Artmed, 2007.

GAMBOA, J. L. H. Los errores en el aprendizajede la matemática. Lima, 1997. Disponível em:

<http://macareo.pucp.edu.pe/ jhenost/articulos/errores.htm>. Acesso em: 29 nov. 2014.

HOUAISS, A. Dicionário eletrônico da língua portuguesa. 3. ed. Rio de Janeiro: Objetiva, 2001. 1 CD-ROM.

LUPIÁÑEZ, J. L. Análisis didáctico: La planificación Del aprendizaje desde uma perspectiva curricular. IN: Rico, Luis; Lupiáñez, José Luis; Molina, Marta. (Org.). Análisis didáctico em 
educación matemática: metodología de investigación, formación de profesores e innovación curricular. Granada, 2013, p. 81-101.

MOVSHOVITZ-HADAR, N.; ZASLAVSKY, O.; INBAR, S. An empirical classification model for errors in high school mathematics. Journal for Research in Mathematics Education, v. 18, n. 1, p. 3-14, 1987.

PINTO, N. B. O erro como estratégia didática. São Paulo: Papirus, 2000.

RADATZ, H. Error Analysis in the Mathematics Education. Journal for Research in Mathematics Education, v. 9, p. 163-172, 1979.

RAMOS, M. L. P. D. Detecção, identificação e retificação: as três fases no tratamento e na correção dos erros. In: ENCONTRO NACIONAL DE EDUCAÇÃO MATEMÁTICA, 11 ., 2013, Curitiba. Anais... Curitiba: ENEM-PR, p. 1-14, 2013. 1 CD-ROM.

RAMOS, M. L. P. D; CURI, E. Análise de erro em avaliação de sistemas digitais: uma questão com lógica AND e flip-flop. Revista Eletrônica em Educação Matemática, Florianópolis, v. $8, \quad$ n. 1, p. 232-247, 2013. Disponível em: $<$ https://periodicos.ufsc.br/index.php/revemat/article/view/1981-1322.2013v8n1p232/ 25136>. Acesso em: 13 jan. 2015.

RAMOS, M. L. P. D.; CURI, E. Modelo de Análise Didática dos Erros: um guia para analisar e tratar erros referentes à função polinomial do $2^{\circ}$ grau. Revista Eletrônica em Educação Matemática, Florianópolis, v. 9, n. 1, p. 27-42, 2014. Disponível em: $<$ https://periodicos.ufsc.br/index.php/revemat/article/view/1981-1322.2014v9n1p27/27617>. Acesso em: 28 jan. 2015.

RICO, L. Errores y dificuldades en el aprendizaje de las matemáticas. In: KILPATRICK, J.; GOMES, P. e RICO, L. Educación matemática. Bogotá: Grupo Editorial Iberoamérica, 1998, p. 69-108. Disponível em: <http://funes.uniandes.edu.co/679/1/KilpatrickEducacion.pdf >. Acesso em: 25 dez. 2014.

SANTOS, J. R. V.; BURIASCO, R. L. C. Da ideia de 'erro' para as maneiras de lidar: caracterizando nossos alunos pelo que eles têm e não pelo que lhes falta. IN: Buriasco, R. L. C. (Org.). Avaliação e educação matemática. Recife: SBEM, 2008.

SOCAS, M. M. Dificultades, obstáculos y errores en el aprendizaje de las matemáticas en la Educación Secundaria. In: RICO, Luiz (Org.). La educación matemática en la enseñanza secundaria, Barcelona, 1997, p. 125-154.

STAREPRAVO, A. R. A multiplicação na escola fundamental I: análise de uma proposta de ensino. 2010. 262 f. Tese (Doutorado em Educação)-Faculdade de Educação da Universidade de São Paulo, São Paulo, 2010. 